Abstracted/indexed in Academic Search Complete, Asia Journals Online, Bangladesh Journals Online, Biological Abstracts, BIOSIS Previews, CAB Abstracts, Current Abstracts, Directory of Open Access Journals, EMBASE/Excerpta Medica, Google Scholar, HINARI (WHO), International Pharmaceutical Abstracts, Open J-gate, Science Citation Index Expanded, SCOPUS and Social Sciences Citation Index;

ISSN: $1991-0088$

\title{
L-Carnitine supplementation ameliorates serum tumor necrosis factor-alpha and matrix metalloproteinase-3 in knee osteoarthritis women
}

\author{
Reza Mahdavi ${ }^{1}$, Sousan Kolahi², Vahideh Ebrahimzadeh Attari ${ }^{3}$ and Aida Malek Mahdavi ${ }^{2}$ \\ ${ }^{1}$ Nutrition Research Center, Tabriz University of Medical Sciences, Tabriz, Iran; ${ }^{2}$ Connective Tissue Diseases \\ Research Center, Tabriz University of Medical Sciences, Tabriz, Iran; ${ }^{3}$ Kidney Research Center, Tabriz University of \\ Medical Sciences, Tabriz, Iran.
}

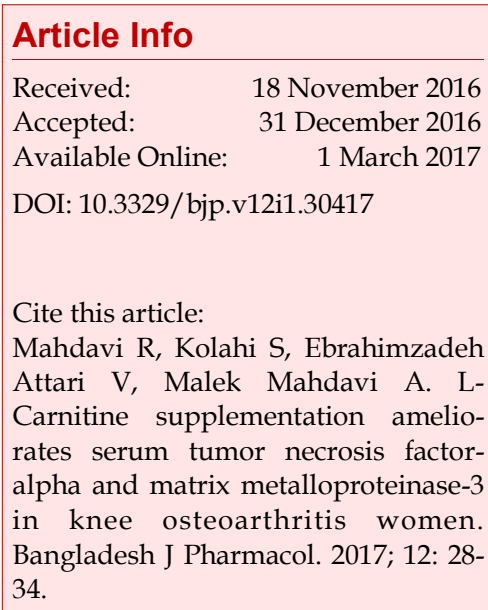

\begin{abstract}
Seventy-two females with mild to moderate knee osteoarthritis were included in this randomized double-blind placebo-controlled study. Patients in the intervention group $(n=36)$ received L-carnitine supplement $(750 \mathrm{mg} /$ day $)$ for two months. L-Carnitine supplementation led to decrease in serum TNF- $\alpha$ and MMP-3 levels significantly in comparison with the baseline $(p<0.001$ and $\mathrm{p}<0.001$, respectively) and placebo group ( $\mathrm{p}<0.001$ and $\mathrm{p}=0.03$, respectively). In addition, physician's global assessment of the severity of osteoarthritis decreased significantly in the L-carnitine group $(\mathrm{p}<0.001)$ and placebo group $(p=0.012)$ after supplementation. At the end of the study, a significant difference was observed between the two groups for mean physician's global assessment of the severity of osteoarthritis $(p<0.001)$, adjusted for baseline values and duration of osteoarthritis. L-Carnitine supplementation has beneficial effects in reducing inflammatory biomarkers in knee osteoarthritis patients which subsequently leads to the alleviation of disease symptoms.
\end{abstract}

\section{Introduction}

Osteoarthritis is the most prevalent type of inflammatory joint disorder, presented by articular cartilage destruction and periarticular bone changes (Felson, 2004). The prevalence of this disease increases significantly with age (Bellare et al., 2014) and is more prevalent in women than men. Since knee is the joint primarily bearing body weight, it is more often affected by osteoarthritis than other joints (Sowers, 2001).

The underlying mechanisms of cartilage degradation are not completely understood but it has been confirmed that inflammatory mediators are directly involved in the regulation of cartilage degradation (Fernandes et al., 2002). It has been indicated that large number of proteinases are found in the synovial fluid in osteoarthritis. The matrix metalloproteinases (MMPs) seem to play a significant role in joint destruction. The MMPs activity is regulated by modulation of production and/or activation from proenzymes and tissue inhibitors of the MMPs (TIMPs) (Andereya et al., 2006). Osteoarthritic cartilage is characterized by the imbalance between MMPs and TIMPs. It has been revealed that levels of matrix-destructive enzymes such as MMP-1, 3 , and -13 increased and those of TIMP-1, a proteinase inhibitor, decreased in osteoarthritis cartilage (Dean et al., 1989; Martel-Pelletier et al., 1994). The inflammatory cytokines interleukin-1-beta (IL-1 $\beta$ ) and tumor necrosis factor alpha (TNF- $\alpha$ ) have been well established in osteoarthritis pathogenesis and are known to increase the secretion of MMPs and reduce the production of TIMPs (Kapoor et al., 2011).

Relieving pain and stiffness and improving physical function are important objectives of therapy in 
osteoarthritis patients (Pendleton et al., 2000). Currently available medication regimens including non-opioid analgesics and non-steroidal anti-inflammatory drugs (NSAIDs) can reduce both pain and inflammation quite effectively, but long-term use of NSAIDs has been found to be associated with high risk for gastrointestinal, heart and renal complications (Phillips and Brasington, 2010; Berenbaum, 2008). Therefore, other effective treatments with more safety are needed.

Recently, non-pharmacological treatments have been studied for the management of osteoarthritis. Dietary supplements are one of the non-pharmacological treatments that attract more attention nowadays and have been studied for controlling osteoarthritis. Lcarnitine is a dietary supplement that has gained popularity and was recently reported to be effective in the management of arthritis (Stoppoloni et al., 2013; Bianchi et al., 2014; Geraci et al., 2012; Kolahi et al., 2015). Previous in vitro and animal studies demonstrated inhibitory effects of L-carnitine on MMPs expression (Bianchi et al., 2014; Deng et al., 2014). Therefore, in an attempt to find new treatments for decreasing inflammation and consequently relieving symptoms in osteoarthritis, this study was designed to assess the effects of L-carnitine treatment on serum TNF-a and MMP-3 in females with knee osteoarthritis.

\section{Materials and Methods}

This study was conducted between November 2013 and December 2014. Sample size calculation was made based on $80 \%$ power and an error of $5 \%$ to detect the treatment effect of L-carnitine on knee pain. Based on these calculations, a total of 60 individuals were needed. Allowing for $20 \%$ dropout over 8 weeks of intervention, the total sample size required for the study was 72 individuals. Inclusion criteria were: Women aged 40-60 years who had mild to moderate bilateral primary knee osteoarthritis according to the American College of Rheumatology criteria (Altman et al., 1986; Massicotte, 2011) and body mass index (BMI) of $25-34.9 \mathrm{~kg} / \mathrm{m}^{2}$. Subjects were selected from the Rheumatology Outpatient Clinic of Tabriz University of Medical Sciences. Subjects who had secondary osteoarthritis (due to a known disorder), surgery, or a joint injection of the target knee within the past 6 months, any serious systematic disease, cardiovascular disease, diabetes mellitus, liver, renal and/or thyroid disorders and any other chronic inflammatory disease, pregnancy and lactation, smoking, alcohol intake, currently taking omega-3-fatty acids (e.g., fish oil) and anti-oxidant supplements, use of NSAIDs two weeks prior to and during the intervention were excluded.

Using a random permuted block procedure (block size 4), women were assigned to two main groups: Experimental group $(n=36)$ received 3 tablets per day of Lcarnitine tartrate supplement $(750 \mathrm{mg} /$ day $)$, and placebo group $(n=36)$ received 3 tablets per day of placebo. The supplements and placebo tablets were identical in appearance and were obtained from Karen Pharmaceutical and Nutrilife Pharmaceutical Co. (Yazd, Iran). The intervention period was 2 months, and subjects were followed by weekly phone contact during this time. The participants were asked to keep their usual dietary intake and physical activity during the study period. Figure 1 presents a diagram of the study design.

$5 \mathrm{~mL}$ of venous blood samples was collected after 12 hours overnight fasting twice (At the beginning and at

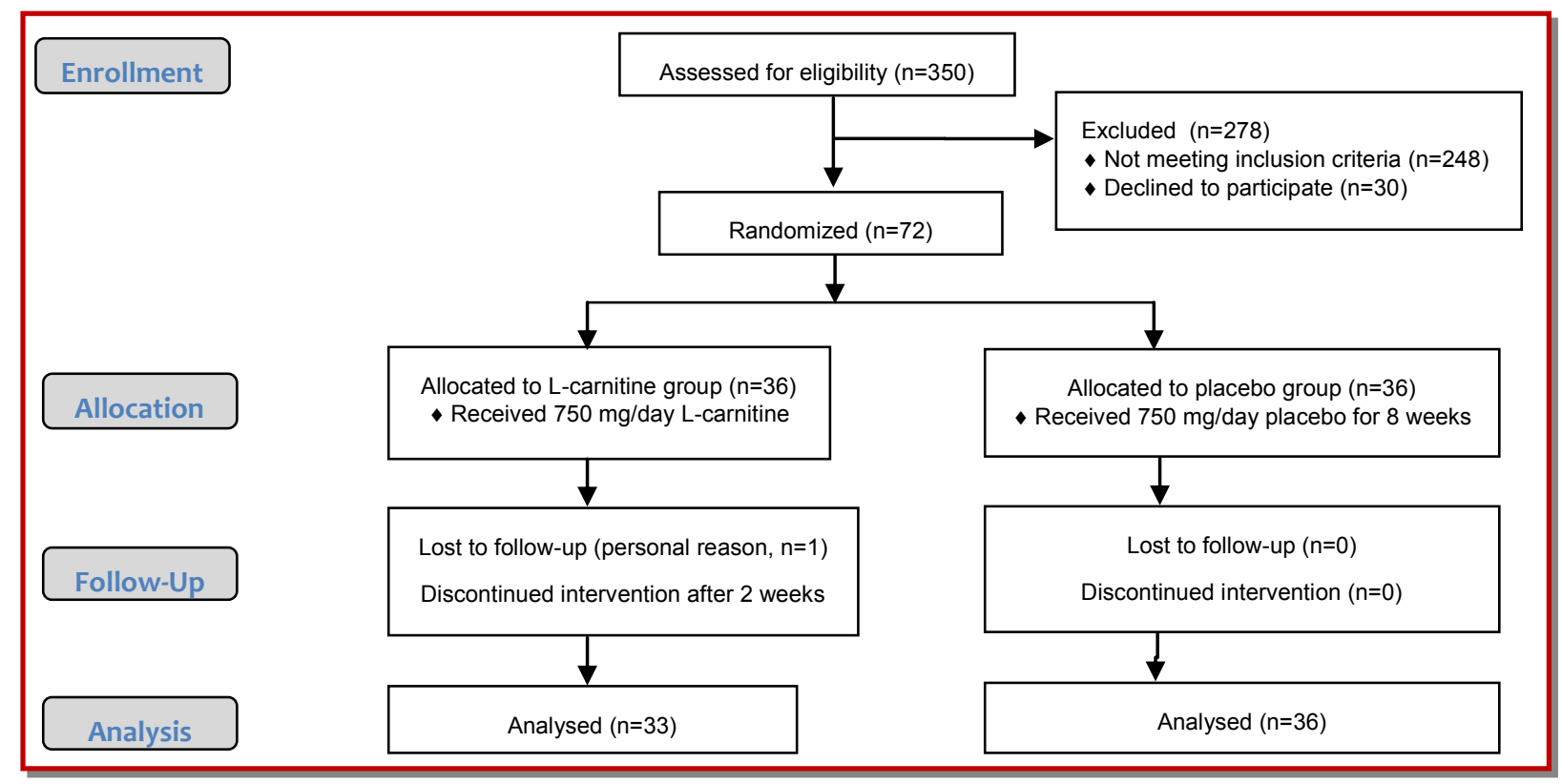

Figure 1: Study flow diagram 
the end of the study). Serum TNF-a levels were determined using platinum enzyme-linked immunosorbent assay (ELISA) kits (Orgenium Laboratories, Finland). Serum MMP-3 levels were determined using human ELISA kits from Boster (Boster Biological Technology Co., Ltd., USA). Using an ELISA plate reader (Model Stat Fax 2100, Awareness, USA) at a wavelength of 450 $\mathrm{nm}$, the color changes were measured. All measurements were done following the instructions provided by the manufacturers.

Physician's global evaluation of response to therapy was also measured on a 0 - to $100-\mathrm{mm}$ visual analog scale (VAS), was performed, where 0 reveals no symptoms and higher scores indicate more severe the disease (Mehta et al., 2007).

All analysis was performed using SPSS software version 16.0 (SPSS, Inc., USA). Normality of variables distribution was evaluated using the KolmogorovSmirnov test. Normally distributed variables were displayed as mean \pm standard deviation. Paired t-test was used to compare differences between variables before and after the intervention. Independent sample $t$ -test was used to compare differences between 2 groups. In order to identify differences between the 2 groups at the end of the study, adjusting for baseline values and duration of osteoarthritis, analysis of covariance (ANCOVA) was used. P value less than 0.05 was considered significant.

\section{Results}

The mean \pm SD age and duration of disease were $51.6 \pm$ 5.7 and $4.1 \pm 3.8$ years in the L-carnitine group and 52.4 \pm 6.6 and $5.8 \pm 5.9$ years in the placebo group, respectively. As presented in Table I, there were no significant differences between the two studied groups at baseline ( $\mathrm{p}>0.05)$.

Table II demonstrates serum biochemical parameters before and after intervention in the two studied groups. There were no significant differences between the two

\begin{tabular}{|l|c|c|c|}
\hline \multicolumn{4}{|c|}{ Table I } \\
\hline \multicolumn{4}{|c|}{ Baseline characteristics of study subjects } \\
\hline Variable & $\begin{array}{c}\text { L-Carnitine } \\
\text { group }(\mathrm{n}=33)\end{array}$ & $\begin{array}{c}\text { Placebo } \\
\text { group }(\mathrm{n}=36)\end{array}$ & $\begin{array}{c}\mathrm{p} \text { val- } \\
\text { ue }^{\mathrm{a}}\end{array}$ \\
\hline Age & 12 & 16 & 0.495 \\
\hline $\begin{array}{l}\text { 40-50 year } \\
\text { 51-60 year }\end{array}$ & 21 & 20 & \\
Body mass index & & & 0.445 \\
$25-29.9 \mathrm{~kg} / \mathrm{m}^{2}$ & 10 & 8 & \\
$30-34.9 \mathrm{~kg} / \mathrm{m}^{2}$ & 23 & 28 & \\
\hline Menopause status & & & 0.933 \\
Not menopause & 15 & 16 & \\
Menopause & 18 & 20 & \\
\hline
\end{tabular}

${ }^{a} \mathrm{p}$ values indicate comparison between groups at baseline ( $\mathrm{X}^{2}$ test)

groups in terms of serum TNF-a and MMP-3 levels at baseline $(\mathrm{p}>0.05)$. Significant decrease was noticed in serum TNF-a levels in the L-carnitine supplemented group $(p<0.001)$, whereas it increased significantly in the placebo group $(p=0.010)$ after the experimental period (Table II). Significant decrease was noticed in serum levels of MMP-3 in the L-carnitine supplemented group ( $\mathrm{p}<0.001)$, whereas it did not change significantly in the placebo group $(\mathrm{p}=0.420)$ after the supplementation period. According to the results of ANCOVA test, there were statistically significant differences between the 2 groups only in serum TNF-a and MMP-3 levels $(p<0.05)$, adjusted for baseline values and duration of osteoarthritis (Table I).

Figure 2 presents the physician's global assessment of the severity of knee osteoarthritis before and after intervention in two groups. At the beginning of the study, there were no significant differences in mean physician's global assessment of the severity of knee osteoarthritis between the 2 groups ( $p>0.05)$. In both Lcarnitine and placebo groups, physician's global assessment of the severity of knee osteoarthritis decreased significantly $(p<0.001$ and $p=0.012$, respectively). According to the results of ANCOVA test,

Table II

Comparison of biochemical variables in treatment groups before and after intervention

\begin{tabular}{|llcrr|}
\hline Variable & Measurement Period & $\begin{array}{c}\text { L-carnitine group } \\
(\mathrm{n}=33)\end{array}$ & $\begin{array}{c}\text { Placebo group } \\
(\mathrm{n}=36)\end{array}$ & $P^{b}$ \\
\hline Serum TNF- $\alpha(\mathrm{pg} / \mathrm{mL})$ & Baseline & $10.2 \pm 7.9$ & $9.2 \pm 6.9$ & 0.571 \\
& After 8 weeks & $9.1 \pm 4.9$ & $10.4 \pm 5.4$ & $<0.001$ \\
& $P a$ & $<0.001$ & 0.010 & 0.291 \\
Serum MMP-3 $(\mathrm{pg} / \mathrm{mL})$ & Baseline & $29.5 \pm 13.3$ & $26.5 \pm 9.5$ & 0.030 \\
& After 8 weeks & $24.5 \pm 12.7$ & $27.7 \pm 11.0$ & 0.420 \\
& $P^{a}$ & $<0.001$ & & \\
\hline
\end{tabular}

Data are presented as Mean \pm SD; aPaired $t$-test; bIndependent sample $t$ test at baseline or ANCOVA test, adjusted for baseline values, and duration of osteoarthritis, after 8 weeks 


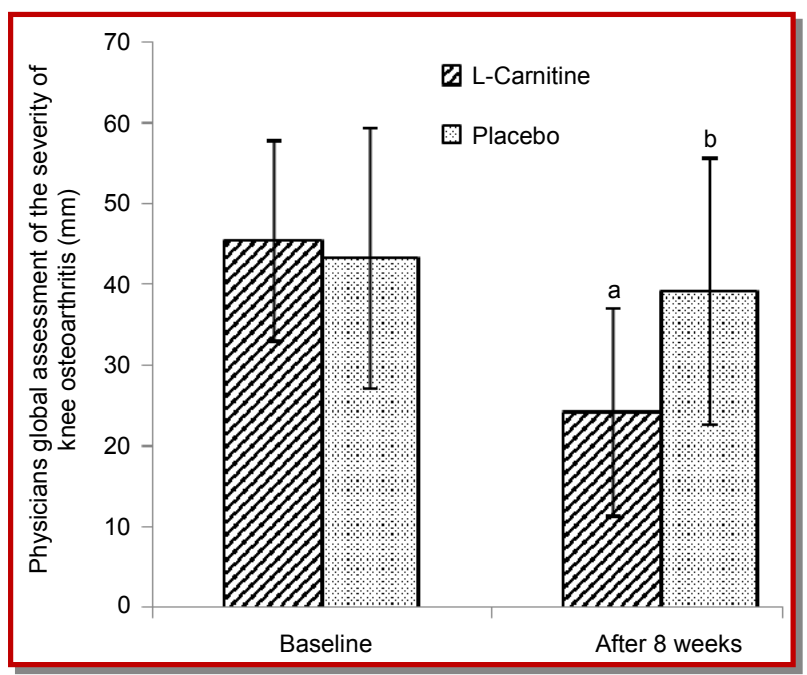

Figure 2. Physician's global assessment of the severity of knee osteoarthritis (100 mm VAS) in the treatment groups at baseline and after 8 weeks. Values are means \pm SD $(n=33$ in the Lcarnitine group and $n=36$ in the placebo group). The mean values were significantly different compared with baseline in both groups (paired t-test): a $>0.05, b p<0.05$. The data were tested using independent-sample $t$ test at baseline and ANCOVA test, adjusted for baseline values and duration of osteoarthritis, after 8 weeks

there were statistically significant differences between the 2 groups in mean physician's global assessment of the severity of knee osteoarthritis $(p<0.001)$, adjusted for baseline values and duration of osteoarthritis.

\section{Discussion}

It has been indicated that development and progression of osteoarthritis involves inflammation even in the primary phases of the disease. Secreted inflammatory factors such as proinflammatory cytokines are critical mediators of the disturbed metabolism and enhanced catabolism of joint tissue involved in osteoarthritis (Kapoor et al., 2011). Among these cytokines, TNF-a has a key role in inducing apoptosis, inflammation, and matrix destruction through stimulating proteolytic enzyme secretion from chondrocytes and synovial fibroblasts (Aktas et al., 2012). Following this biochemical change, the early inflammatory phase of osteoarthritis occurs (Aktas et al., 2012). Therefore, recent studies are focused on the development of new antiinflammatory therapeutic approaches particularly dietary supplementation.

According to our results, a significant difference was found between the two treatment groups in serum level changes of TNF-a through the study. L-carnitine has also been reported to have anti-inflammatory characteristic in previous investigations using animal models (Winter et al., 1995; Vescovo et al., 2002; Idrovo et al., 2012; Liu et al., 2011) and human studies, including patients with type 2 diabetes mellitus (Derosa et al., 2011), nonalcoholic steatohepatitis (Malaguarnera et al., 2010), and coronary artery disease (Lee et al., 2014) and patients undergoing hemodialysis (Shakeri et al., 2010; Duranay et al., 2006; Suchitra et al., 2011). Moreover, our results demonstrated a significant difference between the treatment groups in serum level changes of MMP-3 through the study. Similar to our study, Deng et al. (2014) reported that L-carnitine suppressed the production and activity of MMPs induced by hyperosmolarity in primary human corneal epithelial cells.

It has been shown that in vitro L-carnitine administration decreased NF- $\kappa \beta$ activity, which is responsible for its effects on inducible form of $\mathrm{NO}$ synthase (iNOS) expression at transcriptional level. Decreased NF- $\mathrm{k} \beta$ activity leads to the decrease in iNOS protein expression and nitric oxide synthesis, which has a key role in the pathogenesis of inflammatory diseases (Koc et al., 2011; Moeinian et al., 2013). Furthermore, it has been reported that reactive oxygen species (ROS) may lead to the inflammation which in turn contributes to the increase in expression of proinflammatory cytokines and activation of NF-k $\beta$ pathway (Setia and Sanyal, 2012). NF-kB target genes mainly encode regulators of the immune/inflammatory response, such as cytokines, chemokines, and adhesion molecules (Siomek, 2012). According to previous studies, antioxidants could inhibit NF-k $\beta$. Therefore, in present study, L-carnitine inhibited NF-k $\beta$ and decreased inflammation by suppressing ROS formation (Conner and Grisham, 1996; Kurutas et al., 2005; Cetinkaya et al., 2006). Hua et al. (2014) indicated that L-carnitine suppressed cyclo-oxygenase II expression and ROS formation in human epithelial cells and thus led to the inhibition of proinflammatory cytokines. Considering the role of cyclo-oxygenase enzymes in producing prostaglandins and thromboxane $\mathrm{A} 2$ from arachidonic acid, and the major role of these mediators in developing inflammation and pain in osteoarthritis patients, therefore cyclo-oxygenase inhibition has a major role in decreasing inflammation in osteoarthritis patients (Wittenberg et al., 1993). According to previous findings, levels of leukotriene B4 are increased in osteoarthritis patients which lead to the increase in proinflammatory cytokines. It has been noted that Lcarnitine can inhibit lipo-oxygenase enzyme and decrease synthesis of this leukotriene and consequently decrease inflammation (Atik, 1990; Rainsford et al., 1996; Garrelds et al., 1994; Garrelds et al., 1993; Uzuner et al., 2002; Cho et al., 2015).

Our study indicated significant difference between the treatment groups in physician's global assessment of response to therapy through the study. Similar to our study, Bianchi et al. (2014) showed that acetyl-Lcarnitine was able to reduce pain in osteoarthritis rat 
knee in comparison to the control group. Also, Tastekin et al. (2007) reported that L-carnitine led to the significant improvement in clinical status in rats with adjuvant arthritis. Our findings were consistent with the only similar study carried out by Geraci et al. (2012), in which a food supplement sachet including Lcarnitine fumarate (345 mg) improved clinical symptoms significantly in patients with knee osteoarthritis $(p<0.05)$. Since inflammation has the key role in etiology of pain and stiffness in osteoarthritis (Cho et al., 2015), supplementation with L-carnitine may improve clinical symptoms by decreasing the inflammatory mediators.

\section{Conclusion}

L-carnitine treatment has beneficial effects in reducing inflammatory biomarkers in knee osteoarthritis patients which subsequently leads to alleviation of the disease symptoms.

\section{Ethical Issue}

The study was approved by the Ethics Committee of Tabriz University of Medical Sciences (Iran) and written fully informed consent was obtained from all trial subjects before participating in the study. The trial has been registered at Iranian Registry of Clinical Trials website (code: IRCT201311231197N17).

\section{Acknowledgement}

This article was written based on the data from a PhD thesis on nutrition, which was registered in Tabriz University of Medical Sciences, Tabriz, Iran (NO. D/36). The authors are grateful for financial support from Nutrition Research Center and Vice Chancellor for Research of Tabriz University of Medical Sciences. We thank all the patients for their participation in this study.

\section{Conflict of Interest}

All authors have completed the ICMJE uniform disclosure form and declare no support from any organization for the submitted work.

\section{References}

Altman R, Asch E, Bloch D, Bole G, Borenstein D, Brandt K, Christy W, Cooke TD, Greenwald R, Hochberg M et al. Development of criteria for the classification and reporting of osteoarthritis. Classification of osteoarthritis of the knee. Diagnostic and Therapeutic Criteria Committee of the American Rheumatism Association. Arthritis Rheum. 1986; 29: 1039-49.

Aktas E, Sener E, Zengin O, Uyar Gocun P, Deveci MA. Serum
TNF-alpha levels: Potential use to indicate osteoarthritis progression in a mechanically induced model. Eur J Orthop Surg Traumatol. 2012; 22: 119-22.

Andereya S, Streich N, Schmidt-Rohlfing B, Mumme T, Mu* ller-Rath R, Schneider U. Comparison of modern marker proteins in serum and synovial fluid in patients with advanced osteoarthrosis and rheumatoid arthritis. Rheumatol Int. 2006; 26: 432-38.

Anonymous: Recommendations for the medical management of osteoarthritis of the hip and knee: 2000 update: American College of Rheumatology Subcommittee on Osteoarthritis Guidelines. Arthritis Rheum, 2000; 43: 1905-15.

Atik SO. Leukotriene B4 and prostaglandin E2 activity in synovial fluid in osteoarthritis. Prostaglandins Leukot Essent Fatty Acids. 1990; 39: 253-54.

Bellare N, Argekar H, Bhagwat A, Situt V, Pandita N. Glucosamine and chondroitin sulphate supplementation along with diet therapy provides better symptomatic relief in osteoarthritic patients as compared to diet therapy alone. Int J Pharm Sci Rev Res. 2014; 24: 215-23.

Berenbaum F. New horizons and perspectives in the treatment of osteoarthritis. Arthritis Res Ther. 2008; 10 (Suppl 2): S1.

Bianchi E, Mannelli LDC, Menicacci C, Lorenzoni P, Aglianò M, Ghelardini C. Prophylactic role of acetyl-L-carnitine on knee lesions and associated pain in a rat model of osteoarthritis. Life Sci. 2014; 106: 32-39.

Cetinkaya A, Bulbuloglu E, Kantarceken B, Ciralik H, Kurutas EB, Buyukbese MA, Gumusalan Y. Effects of L-carnitine on oxidant/anti-oxidant status in acetic acid-induced colitis. Dig Dis Sci. 2006; 51: 488-94.

Cho H, Walker A, Williams J, Hasty KA. Study of osteoarthritis treatment with anti-inflammatory drugs: Cyclooxygenase -2 inhibitor and steroids. Bio Med Res Int. 2015; 2015: 1-11.

Conner EM, Grisham MB. Inflammation, free radicals and antioxidants. Nutrition 1996; 12: 274-77.

Dean DD, Martel-Pelletier J, Pelletier JP, Howell DS, Woessner JF. Evidence for metalloproteinase and metalloproteinase inhibitor imbalance in human osteoarthritic cartilage. J Clin Invest. 1989; 84: 678-85.

Deng R, Su Z, Hua X, Zhang Z, Li DQ, Pflugfelder SC. Osmoprotectants suppress the production and activity of matrix metalloproteinases induced by hyperosmolarity in primary human corneal epithelial cells. Mol Vis. 2014; 20: 1243-52.

Derosa G, Maffioli P, Ferrari I, D’Angelo A, Fogari E, Palumbo I, Randazzo S, Cicero AF. Comparison between orlistat plus L-carnitine and orlistat alone on inflammation parameters in obese diabetic patients. Fundam Clin Pharmacol. 2011; 25: 642-51.

Duranay M, Akay H, Yilmaz FM, Senes M, Tekeli N, Y€ucel D. Effects of L-carnitine infusions on inflammatory and nutritional markers in haemodialysis patients. Nephrol Dial Transplant. 2006; 21: 3211-14.

Felson DT. An update on the pathogenesis and epidemiology of osteoarthritis. Radiol Clin North Am. 2004; 42: 1-9.

Fernandes JC, Martel-Pelletier J, Pelletier JP. The role of cytokines in osteoarthritis pathophysiology. Biorheology 2002; 


\section{9: $237-46$}

Geraci A, Zatta D, Strazzabosco C, Tomasello G, Alongi G, Genovese M, Sanfilippo A, D'Arienzo M. The clinical effectiveness of glucosamine sulfate, chondroitin sulfate, hydrolyzed collagen type II, hydrolyzed hyaluronic acid and L-carnitine supplement in patients with osteoarthritis of the knee: A multicenter randomized double blind controlled clinical trial. Minerva Ortop Traumatol. 2012; 63: 9-17.

Garrelds IM, Elliott GR, Pruimboom WM, Zijlstra FJ, Bonta IL. Effects of carnitine and its congeners on eicosanoid discharge from rat cells: Implications for release of TNFa. Mediators Inflamm. 1993; 2: S57-62.

Garrelds IM, Elliott GR, Zijlstra FJ, Bonta IL. Effects of shortand long-term feeding of L-carnitine and congeners on the production of eicosanoids from rat peritoneal leucocytes. Brit J Nutr. 1994; 72: 785-93.

Hua X, Deng R, Zhang Z, Su Z, De-Quan L, Pflugfelder SC. LCarnitine suppresses the production of pro-inflammatory cytoiknes by preventing the hyperosmolarity-induced oxidative stress in human corneal epithelial cells. IOVS 2014; 55: 3058 .

Idrovo JP, Yang WL, Matsuda A, Nicastro J, Coppa GF, Wang P. Post-treatment with the combination of 5-aminoimidazole -4-carboxyamide ribonucleoside and carnitine improves renal function after ischemia/reperfusion injury. Shock 2012; 37: 39-46.

Kapoor M, Martel-Pelletier J, Lajeunesse D, Pelletier JP, Fahmi $\mathrm{H}$. Role of proinflammatory cytokines in the pathophysiology of osteoarthritis. Nat Rev Rheumatol. 2011; 7: 33-42.

Koc A, Ozkan T, Karabay AZ, Sunguroglu A, Aktan F. Effect of L-carnitine on the synthesis of nitric oxide in RAW 264A7 murine macrophage cell line. Cell Biochem Funct 2011; 29: $679-85$.

Kolahi S, Malek Mahdavi A, Mahdavi R, Lak S. Effect of 1carnitine supplementation on clinical symptoms in women with osteoarthritis of the knee: A randomized, double-blind, placebo-controlled trial. Eur J Integ Med. 2015; 7: 540-46.

Kurutas EB, Cetinkaya A, Bulbuloglu E, Kantarceken B. Effects of anti-oxidant therapy on leukocyte myeloperoxidase and $\mathrm{Cu} / \mathrm{Zn}$-superoxide dismutase and plasma malondialdehyde levels in experimental colitis. Mediators Inflamm. 2005; 2005: 390-94.

Lee BJ, Lin JS, Lin YC, Lin PT. Anti-inflammation effects of Lcarnitine supplementation $(1000 \mathrm{mg} / \mathrm{d})$ in coronary artery disease patients. Nutr J. 2014; 31: 79-85.

Liu S, Wu HJ, Zhang ZQ, Chen Q, Liu B, Wu JP, Zhu L. LCarnitine ameliorates cancer cachexia in mice by regulating the expression and activity of carnitine palmityl transferase. Cancer Biol Ther. 2011; 12: 125-30.

Malaguarnera M, Gargante MP, Russo C, Antic T, Vacante M, Malaguarnera M, Avitabile T, Li Volti G, Galvano F. LCarnitine supplementation to diet: A new tool in treatment of nonalcoholic steatohepatitis-a randomized and controlled clinical trial. Am J Gastroenterol. 2010; 105: 133845 .

Martel-Pelletier J, McCollum R, Fujimoto N, Obata K, Cloutier JM, Pelletier JP. Excess of metalloproteinases over tissue inhibitor of metalloproteinase may contribute to cartilage degradation in osteoarthritis and rheumatoid arthritis. Lab Invest. 1994; 70: 807-15.

Massicotte F. Epidemiology of osteoarthritis. In: Understanding osteoarthritis from bench to bedside. Martel-Pelletier J, Pelletier JP (eds). Kerala, India, Research Signpost, 2011, pp 1 $-26$.

Mehta K, Gala J, Bhasale S, Naik S, Modak M, Thakur H, Deo $\mathrm{N}$, Miller MJ. Comparison of glucosamine sulfate and a polyherbal supplement for the relief of osteoarthritis of the knee: A randomized controlled trial. BMC Complement Altern Med. 2007; 7: 34-46.

Moeinian M, Ghasemi-Niri SF, Mozaffari S, Abdollahi M. Synergistic effect of probiotics, butyrate and L-Carnitine in treatment of IBD. JMHI. 2013; 7: 50-53.

Pendleton A, Arden N, Dougados M, Doherty M, Bannwarth B, Bijlsma JW, Cluzeau F, Cooper C, Dieppe PA, Günther KP, Hauselmann HJ, Herrero-Beaumont G, Kaklamanis PM, Leeb B, Lequesne M, Lohmander S, Mazieres B, Mola EM, Pavelka K, Serni U, Swoboda B, Verbruggen AA, Weseloh G, Zimmermann-Gorska I. EULAR recommendations for the management of osteoarthritis: Report of task force standing committee for international clinical studies including therapeutic trials (ESCISIT). Ann Rheum Dis. 2000; 59: $936-44$

Phillips CR, Brasington RD. Osteoarthritis treatment update: Are NSAIDs still in the picture? Musculoskelet Med. 2010; 27: 65-71.

Rainsford KD, Ying C, Smith F. Effects of 5-lipoxygenase inhibitors on interleukin production by human synovial tissues in organ culture: Comparison with interleukin-1synthesis inhibitors. J Pharm Pharmacol. 1996; 48: 46-52.

Setia S, Sanyal SN. Nuclear factor kappa B: A proinflammatory, transcription factor-mediated signalling pathway in lung carcinogenesis and its inhibition by nonsteroidal anti-inflammatory drugs. J Environ Pathol Toxicol Oncol. 2012; 31: 27-37.

Shakeri A, Tabibi H, Hedayati M. Effects of L-carnitine supplement on serum inflammatory cytokines, C-reactive protein, lipoprotein (a), and oxidative stress in hemodialysis patients with Lp (a) hyperlipoproteinemia. Hemodial Int. 2010; 14: 498-504.

Siomek A. NF-кB signaling pathway and free radical impact. Acta Biochim Pol. 2012; 59: 323-31.

Sowers M. Epidemiology of risk factors for osteoarthritis: Systemic factors. Curr Opin Rheumatol. 2001; 13: 447-51.

Stoppoloni D, Politi L, Dalla Vedova P, Messano M, Koverech A, Scandurra R, Scotto d'Abusco A. L-Carnitine enhances extracellular matrix synthesis in human primary chondrocytes. Rheumatol Int. 2013; 33: 2399-403.

Suchitra MM, Ashalatha VL, Sailaja E, Rao AM, Reddy VS, Bitla AR, Sivakumar $V$, Rao PV. The effect of L-carnitine supplementation on lipid parameters, inflammatory and nutritional markers in maintenance hemodialysis patients. Saudi J Kidney Dis Transpl. 2011; 22: 1155-59.

Tastekin N, Aydogdu N, Dokmeci D, Usta U, Birtane M, Erbas $\mathrm{H}$, Ture $M$. Protective effects of L-carnitine and alpha-lipoic 
acid in rats with adjuvant arthritis. Pharmacol Res. 2007; 56: 303-10.

Uzuner N, Kavukcu S, Yilmaz O, Ozkal S, Islekel H, Karaman $\mathrm{O}$, Soylu A, Kargi A. The role of L-carnitine in treatment of a murine model of asthma. Acta Med. 2002; 56: 295-301.

Vescovo G, Ravara B, Gobbo V, Sandri M, Angelini A, Della Barbera M, Dona $M$, Peluso $G$, Calvani $M$, Mosconi L, Dalla Libera L. L-Carnitine: A potential treatment for blocking apoptosis and preventing skeletal muscle myopathy in heart failure. Am J Physiol Cell Physiol. 2002; 283: 802-10.

Winter BK, Fiskum G, Galo LL. Effects of L-carnitine on serum triglyceride and cytokine levels in rat models of cachexia and septic shock. Br J Cancer. 1995; 72: 1173-79.

Wittenberg RH, Willburger RE, Kleemeyer KS, Peskar BA. In vitro release of prostaglandins and leukotrienes from synovial tissue, cartilage, and bone in degenerative joint disease. Arthritis Rheum. 1993; 36: 1444-50. 


\section{Your feedback about this paper}

1. Number of times you have read this paper 0

2. Quality of paper Click

3. Your comments

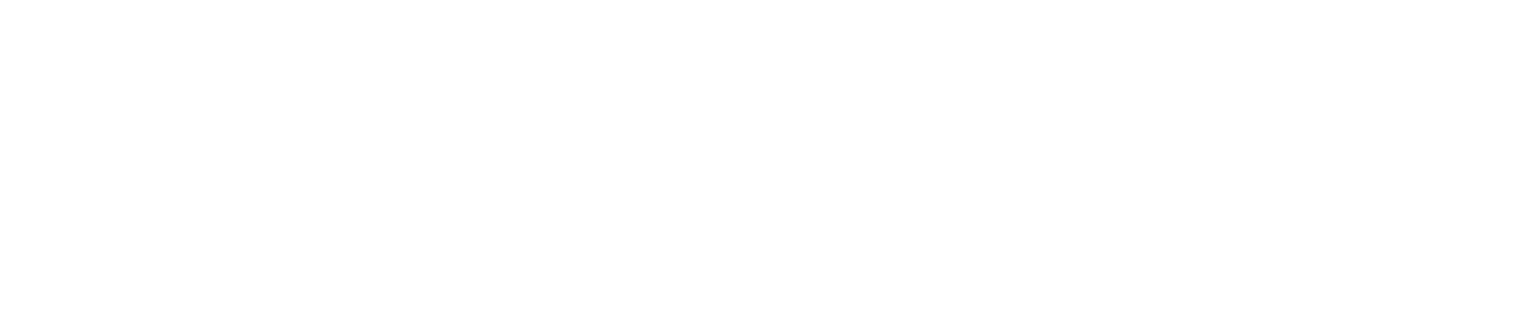

